\title{
Ongoing Use of SSRIs Does Not Alter Outcome in Hospitalized COVID-19 Patients: A Retrospective Analysis
}

\author{
Steven H. Rauchman ${ }^{1, *}$, Sherri G. Mendelson ${ }^{2}$, Courtney Rauchman ${ }^{1}$, Lora J. Kasselman ${ }^{3}$, Aaron Pinkhasov ${ }^{3}$ \\ and Allison B. Reiss ${ }^{3}$ (D) \\ 1 The Fresno Institute of Neuroscience, Fresno, CA 93730, USA; cbr.courtney@gmail.com \\ 2 Providence Southern California Region, Irvine, CA 92612, USA; Sherri.Mendelson@providence.org \\ 3 Department of Medicine and Biomedical Research Institute, NYU Long Island School of Medicine, \\ Mineola, NY 11501, USA; Lora.Kasselman@NYULangone.org (L.J.K.); \\ Aron.Pinkhasov@NYULangone.org (A.P.); Allison.Reiss@NYULangone.org (A.B.R.) \\ * Correspondence: dr.rauchman@yahoo.com
}

check for

updates

Citation: Rauchman, S.H.;

Mendelson, S.G.; Rauchman, C.;

Kasselman, L.J.; Pinkhasov, A.;

Reiss, A.B. Ongoing Use of SSRIs

Does Not Alter Outcome in

Hospitalized COVID-19 Patients:

A Retrospective Analysis. J. Clin.

Med. 2022, 11, 70. https://doi.org/

$10.3390 / j \mathrm{~cm} 11010070$

Academic Editor: Hiroshi Nishiura

Received: 2 November 2021

Accepted: 17 December 2021

Published: 24 December 2021

Publisher's Note: MDPI stays neutral with regard to jurisdictional claims in published maps and institutional affiliations.

Copyright: (C) 2021 by the authors. Licensee MDPI, Basel, Switzerland. This article is an open access article distributed under the terms and conditions of the Creative Commons Attribution (CC BY) license (https:// creativecommons.org/licenses/by/ $4.0 /)$.

\begin{abstract}
SARS-CoV-2 continues to have devastating consequences worldwide. Though vaccinations have helped reduce spread, new strains still pose a threat. Therefore, it is imperative to identify treatments that prevent severe COVID-19 infection. Recently, acute use of SSRI antidepressants in COVID+ patients was shown to reduce symptom severity. The aim of this retrospective observational study was to determine whether COVID+ patients already on SSRIs upon hospital admission had reduced mortality compared to COVID+ patients not on chronic SSRI treatment. Electronic medical records of 9044 patients with laboratory-confirmed COVID-19 from six hospitals were queried for demographic and clinical information. Using $\mathrm{R}$, a logistic regression model was run with mortality as the outcome and SSRI status as the exposure. In this sample, no patients admitted on SSRIs had them discontinued. There was no significant difference in the odds of dying between COVID+ patients on chronic SSRIs vs. those not taking SSRIs, after controlling for age category, gender, and race. This study shows the utility of large clinical databases in determining what commonly prescribed drugs might be useful in treating COVID-19. During pandemics due to novel infectious agents, it is critical to evaluate safety and efficacy of drugs that might be repurposed for treatment.
\end{abstract}

Keywords: COVID-19; disease severity; clinical presentation; SSRI; antidepressant

\section{Introduction}

The COVID-19 pandemic has resulted in an unprecedented worldwide response in the form of a multitude of clinical trials designed to develop efficacious prophylactic and therapeutic interventions [1]. The life-threatening global health crisis has encouraged innovation with a focus on rapid results and this has led to the evaluation of existing pharmaceuticals for potential repurposing as COVID-19 treatments [2,3]. The low cost and widespread availability of some drugs already on the market has made them attractive from a social and medical perspective. A number of anti-viral agents are under investigation, but are still pending formal approval in the United States $[4,5]$. Unfortunately, the true efficacy of some of these compounds has not been supported by more rigorous clinical trials [6].

The common usage of psychotropic drugs in the general population has led to an interest in their effects on the course and mortality of patients diagnosed with COVID-19. Crisanto Diez Quevedo et al. provide one of the most comprehensive studies of psychiatric diagnosis and use of psychotropic drugs before and during hospitalization for COVID19 [7]. This observational study analyzed 2150 patients hospitalized with COVID-19 with a variety of psychiatric comorbidities who received psychotropic drug treatments of different drug classes, and was not a dedicated SSRI study. In this group, 14\% were already on psychopharmacological treatments, while $41.4 \%$ were prescribed psychotropic drugs de novo upon or after admission to the hospital. SSRIs were prescribed, but other anti-anxiety 
drugs were more commonly administered. Mortality rate was $17 \%$ and $14 \%$ required admission to an ICU. History of depressive disorders, and development of delirium during admission, were associated with higher mortality. They found an association between use of anxiolytics/hypnotics or antidepressants during the previous and reduced mortality, but could not confirm any cause-and-effect relationship.

The potential value of selective serotonin reuptake inhibitors (SSRIs) and selective norepinephrine reuptake inhibitors (SNRIs), typically prescribed for anxiety, depression and obsessive-compulsive disorder (OCD), has been discussed significantly in the scientific literature [8] and lay press [9]. Numerous in vitro studies have carefully delineated multiple inflammatory pathways in which SSRIs and SNRIs might be beneficial in reducing inflammation [10-14]. The key role of inflammation in the progression, morbidity, and mortality of COVID-19 has been well documented in the medical literature and cytokine storm syndrome is a life-threatening feature of severe COVID-19 [8,15-17]. Depressed persons often exhibit raised blood levels of proinflammatory cytokines and SSRIs may reduce these levels $[18,19]$. Anti-inflammatory effects of SSRIs may thus underlie their possible protective role in COVID-19 [11]. Serotonin may have a direct effect on the immune system and COVID-19 may induce serotonin deficiency [20,21]. An example of serotonin's effect on the immune system is seen in T lymphocytes where SSRIs decrease their viability and immunoreactive protein content [22]. SSRIs have been found to dampen key inflammatory pathways such as the signal transducer and activator of transcription 3 (STAT3) and nuclear factor (NF)-kB pathways [9]. This, in turn, attenuates downstream proinflammatory cytokine expression, notably that of interleukin- 6 and tumor necrosis factor (TNF)- $\alpha$, both of which are implicated in cytokine storm [23,24].

Fluoxetine and other SSRIs might have a direct anti-viral effect $[25,26]$. Interestingly, it has been found that the COVID-19 virus activates the ceramide system that then facilitates viral entry into cells [27]. The sphingomyelin/ceramide system can be altered by SSRIs so that ceramide levels are reduced and this may prevent COVID-19 replication [28-30].

Early in the pandemic, a large French multi-center retrospective study [8] suggested the beneficial role of SSRIs in preventing intubation and death in hospitalized COVID-19 patients. The SSRIs needed to be continued within the first $48 \mathrm{~h}$ of hospital admission. The prior use of these drugs in individuals as outpatients before contracting COVID-19 is not clearly described. There was also a noteworthy exclusion of many patients because of incomplete medical records. A key limitation of this ambitious and important review is the sudden inundation of the French health care system with large numbers of very sick COVID-19 patients. The retrospective nature of the study was intended to encourage more rigorous prospective investigations.

There have since been a number of publications on SSRIs and COVID-19, and these have garnered attention from the lay press. Stories have appeared in the Los Angeles Times and CBS News and the subject was featured on the national television news magazine program "60 Minutes". The importance of exploring the role of SSRIs in COVID was noted in Nature by a co-author of this paper, Steven Rauchman [31]. With the presence of effective vaccines, conducting a large prospective clinical trial of therapeutics in the US, Europe, and other nations with large vaccination programs loses feasibility. Simply stated, those fortunate populations cease being a control or treatment group available for potential therapeutic drugs, yet the need for effective therapeutics to prevent suffering and death among a significant part of the world population remains. Vaccines will not reach many less advantaged nations in time and, with new strains, breakthrough cases are emerging in vaccinated populations [32]. The omicron variant is the most recent to cause concern due to its high transmissibility and large number of mutations in the spike protein, responsible for virus invasion of host cells [33].

The purpose of this study is to explore the utility of SSRIs in the setting of acute COVID-19 illness, not only as a means to resolve the issue of its effectiveness, but to provide a paradigm for evaluating repurposed drugs and to address the issue of maintenance medication continuation/discontinuation decisions in the acute care setting. 


\section{Materials and Methods}

This study was approved by the Providence Health and Services IRB as a minimal risk study on 31 March 2021. Providence Health and Services IRB is an electronic IRB serving the 52 hospitals and 1085 clinics within the large Providence System located in 7 states along the West Coast. Providence Health and Services IRB is compliant with U.S. Health and Human Services regulations and requires CITI training and conflict of interest attestations for all investigators. All research studies are required to obtain IRB approval or exemption prior to initiation. There are more than 1700 published studies with Providence Health and Services IRB approval. A retrospective observational study design was used. Therefore, it was determined by the IRB that consent would be waived. Electronic medical records of 9044 patients with a laboratory-confirmed diagnosis of COVID-19 from March 2020 to March 2021 from six hospitals were queried for discharge date and disposition; medications on admission including SSRIs/SNRIs; age; gender; ethnicity; admission to ICU; discontinuation of antidepressant medications upon ICU admission, and hospital facility.

Inclusion criteria: adult patients 18 and over admitted with a diagnosis of COVID-19 and on an antidepressant drug during admission.

Exclusion criteria: patients under 18 years of age, without an admission diagnosis of COVID-19 and not on an antidepressant drug on admission.

Using R version 3.6.2 (R Core Team, 2021, open source, R Foundation for Statistical Computing, Vienna, Austria), a logistic regression model was run with mortality as the outcome and SSRI status as the exposure. Initially, anti-depressant drugs were separated out (SSRI status; SSRIs vs. SNRIs) in the model but since there were no significant differences among the drug classes, they were combined in the final models. An adjusted logistic regression model was run to account for age category, gender, race, and hospital facility. All tests were considered significant at $\mathrm{p}$ of 0.05 or less. For inclusion in the statistical model, age category $(<18,18-30,31-40,41-50,51-60,61-70,71-80,81+$ years $)$ was recoded into the median year for each age range. One person was dropped from the analysis because their self-reported gender (female, male) was listed as "unknown". Self-reported race categories were White or Caucasian, Hispanic or Latino, Black or African-American, Asian, Native Hawaiian or Other Pacific Islander, American Indian or Alaska Native, Other, Unknown. Any person who indicated "refused to answer" or had missing race information was categorized as "Unknown" for the analysis. Hospital facility names were Providence Holy Cross Medical Center, Providence Little Company of Mary (San Pedro), Providence Little Company of Mary (Torrance), Providence Saint John's Health Center, Providence St. Joseph Medical Center (Burbank), and Providence Tarzana Medical Center.

\section{Results}

Figure 1 is a flow chart of the retrospective cohort study.

Demographic information on our population is shown in Table 1. Of the 832 patients that continued taking SSRIs/SNRIs, the following were represented: citalopram hydrobromide $(n=109)$, desvenlafaxine $(n=1)$, duloxetine $\mathrm{HCl}(n=145)$, escitalopram oxalate $(n=227)$, fluoxetine $\mathrm{HCl}(n=87)$, paroxetine $\mathrm{HCl}(n=48)$, sertraline $\mathrm{HCl}(n=175)$, and venlafaxine $\mathrm{HCl}(n=40)$. The odds of dying do not differ significantly in hospitalized COVID+ patients based on whether or not they are taking SSRIs/SNRIs (Table 2). 


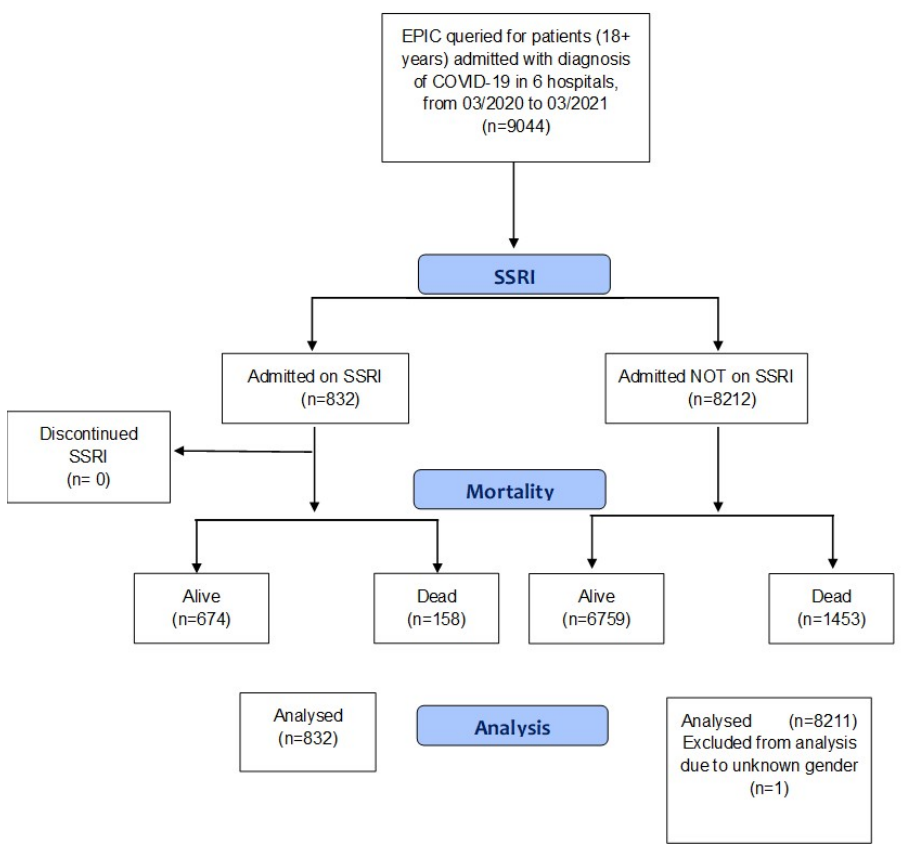

Figure 1. Flow chart of retrospective cohort study of COVID-19 hospitalized patients categorized by use/non-use of SSRIs on admission and subsequent continuation/discontinuation of SSRIs. Scheme depicts study design, cohort selection, and outcome.

Table 1. Demographic information.

\begin{tabular}{|c|c|c|}
\hline Demographic & Patients on SSRIs/SNRIs (\%) & Patients Not on SSRIs/SNRIs (\%) \\
\hline & $n=832$ & $n=8211$ \\
\hline \multicolumn{3}{|l|}{ Gender } \\
\hline Female & $504(60.6)$ & $3646(44.4)$ \\
\hline Male & $328(39.4)$ & $4565(55.6)$ \\
\hline \multicolumn{3}{|l|}{ Age Group } \\
\hline$>81$ & $248(29.8)$ & $1623(19.8)$ \\
\hline $71-80$ & $203(24.4)$ & $1489(18.1)$ \\
\hline $61-70$ & $181(21.8)$ & $1683(20.5)$ \\
\hline $51-60$ & $93(11.2)$ & $1458(17.8)$ \\
\hline $41-50$ & $59(7.1)$ & $799(9.7)$ \\
\hline $31-40$ & $35(4.2)$ & $663(8.1)$ \\
\hline $18-30$ & $13(1.6)$ & $455(5.5)$ \\
\hline$<18$ & $0(0.0)$ & $41(0.5)$ \\
\hline \multicolumn{3}{|l|}{ Primary Race } \\
\hline White or Caucasian & 409 (49.2) & $2151(26.2)$ \\
\hline Hispanic or Latino & $277(33.3)$ & $4196(51.1)$ \\
\hline Black or African American & $43(5.2)$ & $493(6.0)$ \\
\hline Asian & $28(3.4)$ & $476(5.8)$ \\
\hline Native Hawaiian or Other Pacific Islander & $2(0.2)$ & $60(0.7)$ \\
\hline American Indian or Alaskan Native & $0(0.0)$. & $5(0.1)$ \\
\hline Other & $61(7.3)$ & $683(8.3)$ \\
\hline Unknown & $12(1.4)$ & $147(1.8)$ \\
\hline \multicolumn{3}{|l|}{ Facility Name } \\
\hline Providence Holy Cross Med Center & $2277(27.7)$ & $186(22.4)$ \\
\hline Providence Little Company of Mary (San Pedro) & $450(5.5)$ & $41(4.9)$ \\
\hline Providence Little Company of Mary (Torrance) & $2262(27.5)$ & $137(16.5)$ \\
\hline Providence Saint John's Health Center & $607(7.4)$ & $103(12.4)$ \\
\hline Providence St. Joseph's Medical Center (Burbank) & $1622(19.8)$ & $209(25.1)$ \\
\hline Providence Tarzana Medical Center & $993(12.1)$ & $156(18.8)$ \\
\hline
\end{tabular}


Table 2. Odds of death in COVID+ patients on continuation of SSRIs/SNRIs during hospitalization.

\begin{tabular}{|c|c|c|c|c|}
\hline Variables & Crude ORs (95\% CI) & $p$-Value & Adjusted ORs (95\% CI) & $p$-Value \\
\hline \multicolumn{5}{|l|}{ SSRI on admission: } \\
\hline No & 1 & & 1 & \\
\hline Yes & $1.09(0.91,1.30)$ & 0.353 & $0.96(0.79,1.16)$ & 0.687 \\
\hline \multicolumn{5}{|l|}{ Sex } \\
\hline Female & 1 & & 1 & \\
\hline Male & $1.34(1.20,1.49)$ & $<0.001$ & $1.53(1.36,1.71)$ & $<0.001$ \\
\hline Age category (years) ${ }^{a}$ & $1.04(1.03,1.04)$ & $<0.001$ & $1.04(1.04,1.05)$ & $<0.001$ \\
\hline \multicolumn{5}{|l|}{ Primary race: } \\
\hline White or Caucasian & 1 & & 1 & \\
\hline American Indian or Alaskan Native & $1.09(0.06,7.42)$ & 0.936 & $3.04(0.15,21.5)$ & 0.328 \\
\hline Asian & $1.27(1.00,1.59)$ & 0.047 & $1.54(1.20,1.97)$ & $<0.001$ \\
\hline Black or African American & $0.86(0.67,1.10)$ & 0.236 & $1.20(0.91,1.56)$ & 0.191 \\
\hline Hispanic or Latino & $0.86(0.76,0.98)$ & 0.018 & $1.49(1.28,1.73)$ & $<0.001$ \\
\hline Native Hawaiian or Other Pacific Islander & $0.56(0.23,1.15)$ & 0.148 & $0.98(0.40,2.08)$ & 0.968 \\
\hline Other & $1.12(0.91,1.38)$ & 0.261 & $1.30(1.05,1.61)$ & 0.015 \\
\hline Unknown & $1.52(1.04,2.18)$ & 0.026 & $2.04(1.37,2.99)$ & $<0.001$ \\
\hline \multicolumn{5}{|l|}{ Facility Location Name: } \\
\hline Providence Holy Cross Medical Center & 1 & & 1 & \\
\hline Providence Little Company of Mary (San Pedro) & $0.80(6.1,1.04)$ & 0.107 & $0.87(0.65,1.14)$ & 0.318 \\
\hline Providence Little Company of Mary (Torrance) & $0.95(0.82,1.11)$ & 0.516 & $0.95(0.81,1.12)$ & 0.570 \\
\hline Providence Saint John's Health Center & $1.68(1.38,2.04)$ & $<0.001$ & $1.58(1.27,1.95)$ & $<0.001$ \\
\hline Providence St. Joseph Medical Center (Burbank) & $0.97(8.3,1.14)$ & 0.720 & $0.93(0.78,1.11)$ & 0.411 \\
\hline Providence Tarzana Medical Center & $1.06(0.88,1.27)$ & 0.549 & $1.01(0.83,1.23)$ & 0.934 \\
\hline
\end{tabular}

$\mathrm{CI}=$ confidence interval, $\mathrm{OR}=$ odds ratio, SSRI/SNRI $=$ selective serotonin reuptake inhibitor/selective norepinephrine reuptake inhibitor. ${ }^{\mathrm{a}}=$ reference age category is $<18$ years.

There is no significant difference in the odds of dying between COVID+ patients on SSRIs vs. COVID+ patients not taking SSRIs. The odds of COVID+ patients on SSRIs dying is 1.09 (95\% CI: $0.91,1.31)$ compared to COVID+ patients not on SSRIs $(p=0.35)$. There is no significant difference in the odds of dying between COVID+ patients on SSRIs vs. COVID+ patients not taking SSRIs, after controlling for age category, gender, primary race, and facility location, the odds of COVID+ patients on SSRIs dying are 0.96 (95\% CI: $0.79,1.16)$ compared to COVID+ patients not on SSRIs ( $p=0.69$; Table 2$)$.

\section{Discussion}

As noted previously, the initial study from France that implicated SSRIs as potential therapeutic tools in COVID-19 was beset by a number of limitations [8]. A few other small studies have supported the results from France. In a randomized prospective clinical trial of 152 outpatients with confirmed COVID-19 given either fluvoxamine or placebo, early clinical introduction of fluvoxamine decreased likelihood of clinical deterioration over a 15-day period [34]. The authors readily acknowledged the difficulty in recruiting patients. The short duration and small sample size were other limiting variables. The authors recommended larger prospective clinical trials.

Another important SSRI investigation took place early in the pandemic at a San Francisco Bay Area racetrack [35]. A large number of racetrack employees were diagnosed with COVID-19 in a very brief period of time. The racetrack physician offered fluvoxamine to the infected racetrack employees and approximately 50\% of the employees took the drug while the remainder declined. There was no treatment available for early intervention in COVID-19 at that point in time besides supportive care. According to this study, fluvoxamine prevented serious clinical deterioration and hospitalization.

A larger prospective randomized clinical trial on fluvoxamine was recently completed in Brazil led by investigators from Brazil and Canada [36]. This study appears to support the 
value of fluvoxamine in early intervention in COVID-19 patients in preventing progression, serious complications, and mortality.

A recently published large retrospective study from the University of California, San Francisco, and Stanford University (UCSF/Stanford) suggests that SSRIs may be associated with decreased mortality from COVID [37]. This evaluation of in excess of 80,000 patients found that reduced mortality was confined to those taking fluvoxamine and fluoxetine. Importantly, the authors only considered patients taking SSRIs within a defined time period (10 days before and four days after a diagnosis of COVID-19. Patients with documented SSRI use outside of this window were excluded from the study. This resulted in exclusion of 7250 of the 83,584 patients. In contrast, our retrospective analysis examined a somewhat different patient population, which included all patients taking SSRIs upon hospital admission for presumptive pre-existing psychiatric diagnosis. The underlying assumption under these criteria is that the vast majority had been on SSRIs for a significant period of time. In our study, approximately $10 \%$ of COVID-19 admissions were already on SSRIs. This is similar to the rate of use of this class of drugs in the general population. The UCSF/Stanford study included a population in which $4.1 \%$ of patients were on SSRIs. Presumably, the UCSF/Stanford study includes patients who were being prescribed SSRIs for a very recent diagnosis of a psychiatric disorder or individuals where SSRIs were added after hospital admission and COVID-19 diagnosis. Our study was not focused on the need for acute intervention with SSRIs to treat patients admitted with COVID-19.

The initial inquiry by our group was directed at recreating the original French study. The retrospective review presented here is not a double-blind placebo-controlled randomized clinical trial because that would be costly and difficult to execute in the midst of a pandemic.

A significant segment of the adult population in the United States (estimated at $10-20 \%$ ) is already taking SSRIs and the rate of antidepressant use has been increasing in the last decade [38]. This supports the need to use available data to determine definitively whether patients who are already taking antidepressants fare better or worse than patients not taking such medications. This is especially crucial in more severe COVID-19 cases requiring hospitalization. Our study indicates that, in a population hospitalized for COVID-19, there was no clinical benefit of SSRIs that were being taken before and during admission. Since use of SSRIs for anxiety, OCD or depression seems unrelated to other comorbidities known to affect COVID morbidity and mortality (hypertension, diabetes, heart disease), direct impact of SSRIs on the risk factors for severe COVID-19 is minimal. There is one important caveat-the weight gain that may accompany use of some SSRIs [39].

A limitation of our study is that our patient population did not have any patients taking fluvoxamine and this is in direct contrast to the French study and to an open label, prospective cohort study of fluvoxamine in ICU patients with COVID-19 from Croatia [8,40]. In the Croatian group, 51 COVID-19 patients with severe disease admitted to the ICU were started on fluvoxamine $100 \mathrm{mg}$ three times per day for 15 days in addition to standard therapy. These patients were prospectively matched to 51 controls with COVID-19 who were not given fluvoxamine. Overall mortality was lower in the fluvoxamine group, $58.8 \%$ than in the control group, $76.5 \%(p=0.027)$.

Our study examined severely ill patients while a recent retrospective observational study from Rockland County, New York, USA, looked at a cohort of 165 long-stay psychiatric facility in-patients and found that those receiving antidepressants had $72 \%$ lower odds of testing positive for COVID-19. SSRIs and SNRIs were the drivers of this significantly decreased likelihood of COVID-19 infection. Outcome once infected with COVID-19 was not assessed in this analysis [41].

Fluvoxamine has been shown to be a sigma-1 receptor (S1R) agonist with the strongest binding affinity to S1R of all the SSRIs [41]. S1R is a chaperone protein located at the endoplasmic reticulum-mitochondrion interface that regulates autophagy, an important process in viral evasion [42]. It has cytoprotective and anti-inflammatory properties [43]. By 
activating S1R, fluvoxamine exerts immunomodulatory effects and can reduce cytokine production [44]. Other SSRIs do not activate S1R as potently and the absence of a fluvoxamine subset of patients may have affected our results [45,46].

Another important clinical issue is whether SSRIs are continued or discontinued when a COVID-19 patient is hospitalized or admitted to an ICU. SSRIs are frequently discontinued in the ICU patient $[42,43]$. There is literature showing that discontinuation results in adverse ICU outcomes [42,43]. SSRIs are often inadvertently discontinued because they are not considered important in acute disease. This can cause increased agitation among these patients and need for additional sedation, which may in turn depress respiration. There are sometimes relative contraindications to SSRI use in ICU patients. ECG changes and coagulation issues have been noted [44,45]. The ICU physicians in this study did not routinely discontinue the use of SSRIs in patients unless medically indicated. Hospital policy is to continue antidepressants while patients are hospitalized. The health organization has a Clinical Institutes model that shares expertise and research across the region's 13 hospitals and affiliated hospitals and this policy was already in existence prior to this study and was not in any manner attributable to this study. As we debate the potential value of such drugs in very sick patients with COVID-19, a collateral effect might be a re-examination of ICU drug protocols for all patients. Among the drug classes with anti-inflammatory properties routinely prescribed in the middle aged and senior populations that merit review are the statins, metformin, and antihypertensives, particularly angiotensin-converting enzyme inhibitors [46-48]. Perhaps there is synergistic activity in patients on several of these medications. Large retrospective studies of these commonly used drugs would begin to resolve these issues.

Clearly, there are many aspects (of timing and situation), with regard to SSRI/SNRI use and the impact on COVID-19 outcome that remain unresolved.

\section{Conclusions}

The impact of psychiatric disorders and SSRIs on COVID-19 evolution and mortality has been referenced in the literature with no clear-cut results $[49,50]$. In the present retrospective study of 9044 patients hospitalized for COVID-19 in six California hospitals of a large hospital system in the Western US, prior use of SSRIs or SNRIs did not reduce mortality. These drugs were continued during hospitalization and had been started prior to the onset of COVID-19, presumably for a pre-existing psychiatric condition.

This study shows the utility of large clinical databases in addressing the urgent issue of determining what commonly prescribed drugs might be useful in treating COVID-19. The ongoing nature of the pandemic despite the vaccine rollout signals a pressing need to mitigate COVID-19 sequelae and the repurposing of readily available and inexpensive medications has the potential to save lives, particularly because rapid implementation could occur. As a result of this study, the use of the SSRI/SNRI drug class does not hold a particular advantage in the patient population already taking these drugs. Our study does not provide evidence that there is any benefit to keeping patients on SSRIs in the ICU. COVID-19 data are already embedded in medical records and available within electronic health systems; thus, filling in the gaps in knowledge, about the effects on morbidity and mortality of specific SSRIs and drug combinations, should be feasible [51].

Author Contributions: Conceptualization, S.H.R. and A.B.R.; methodology, S.G.M. and L.J.K.; formal analysis, S.G.M., L.J.K. and C.R.; writing, A.B.R., S.H.R. and A.P.; review and editing, S.G.M., L.J.K. and A.P.; Software, C.R. and L.J.K. All authors have read and agreed to the published version of the manuscript.

Funding: This work was supported by the Quality Department at Providence Southern California Region.

Institutional Review Board Statement: The study was conducted according to the guidelines of the Declaration of Helsinki, and approved by the Institutional Review Board of the Providence Health and Services (date of approval 31 March 2021). 
Informed Consent Statement: Only anonymized data were used in this study, so consent was not required.

Data Availability Statement: The full dataset is available from the corresponding author, upon motivated request.

Acknowledgments: The authors would like to thank Edmonds Bafford.

Conflicts of Interest: The authors declare no conflict of interest.

\section{References}

1. Kuriakose, S.; Singh, K.; Pau, A.K.; Daar, E.; Gandhi, R.; Tebas, P.; Evans, L.; Gulick, R.M.; Lane, H.C.; Masur, H.; et al. Developing Treatment Guidelines During a Pandemic Health Crisis: Lessons Learned From COVID-19. Ann. Int. Med. 2021, 174, 1151-1158. [CrossRef]

2. Riva, L.; Yuan, S.; Yin, X.; Martin-Sancho, L.; Matsunaga, N.; Pache, L.; Burgstaller-Muehlbacher, S.; De Jesus, P.D.; Teriete, P.; Hull, M.V.; et al. Discovery of SARS-CoV-2 antiviral drugs through large-scale compound repurposing. Nature 2020, 586, 113-119. [CrossRef] [PubMed]

3. Xu, Y.; Chen, K.; Pan, J.; Lei, Y.; Zhang, D.; Fang, L.; Tang, J.; Chen, X.; Ma, Y.; Zheng, Y.; et al. Repurposing clinically approved drugs for COVID-19 treatment targeting SARS-CoV-2 papain-like protease. Int. J. Biol. Macromol. 2021, 188, 137-146. [CrossRef]

4. $\quad$ Chiou, W.C.; Hsu, M.S.; Chen, Y.T.; Yang, J.M.; Tsay, Y.G.; Huang, H.C.; Huang, C. Repurposing existing drugs: Identification of SARS-CoV-2 3C-like protease inhibitors. J. Enzym. Inhib. Med. Chem. 2021, 36, 147-153. [CrossRef] [PubMed]

5. Pickard, A.; Calverley, B.C.; Chang, J.; Garva, R.; Gago, S.; Lu, Y.; Kadler, K.E. Discovery of re-purposed drugs that slow SARS-CoV-2 replication in human cells. PLoS Pathog. 2021, 17, e1009840. [CrossRef] [PubMed]

6. Singh, B.; Ryan, H.; Kredo, T.; Chaplin, M.; Fletcher, T. Chloroquine or hydroxychloroquine for prevention and treatment of COVID-19. Cochrane Database Syst. Rev. 2020, 2020, CD013587. [CrossRef]

7. Diez-Quevedo, C.; Iglesias-González, M.; Giralt-López, M.; Rangil, T.; Sanagustin, D.; Moreira, M.; López-Ramentol, M.; Ibáñez-Caparrós, A.; Lorán, M.E.; Bustos-Cardona, T.; et al. Mental disorders, psychopharmacological treatments, and mortality in 2150 COVID-19 Spanish inpatients. Acta Psychiatr. Scand. 2021, 143, 526-534. [CrossRef] [PubMed]

8. Hoertel, N.; Sánchez-Rico, M.; Vernet, R.; Beeker, N.; Jannot, A.S.; Neuraz, A.; Salamanca, E.; Paris, N.; Daniel, C.; Gramfort, A.; et al. Association between antidepressant use and 426 reduced risk of intubation or death in hospi-talized patients with COVID-19: Results from an 427 observational study. Mol. Psychiatry 2021, 26, 5199-5212. [CrossRef]

9. Lopez, S. Can a Common Antidepressant Help in the Fight against COVID-19? LA Times. 2021. Available online: https://www.latimes com/california/story/2021-02-03/can-common-antidepressant-help-covid-19-fight (accessed on 1 November 2021).

10. Meikle, C.K.S.; Creeden, J.F.; McCullumsmith, C.; Worth, R.G. SSRIs: Applications in inflammatory lung disease and implica-tions for COVID-19. Neuropsychopharmacol. Rep. 2021, 41, 325-335. [CrossRef]

11. Pashaei, Y. Drug repurposing of selective serotonin reuptake inhibitors: Could these drugs help fight COVID-19 and save lives? J. Clin. Neurosci. 2021, 88, 163-172. [CrossRef]

12. Creeden, J.F.; Imami, A.S.; Eby, H.M.; Gillman, C.; Becker, K.N.; Reigle, J.; Andari, E.; Pan, Z.K.; O’Donovan, S.M.; McCullumsmith, R.E.; et al. Fluoxetine as an anti-inflammatory therapy in SARS-CoV-2 infection. Biomed. Pharmacother. 2021, 138, 111437. [CrossRef]

13. Sukhatme, V.P.; Reiersen, A.M.; Vayttaden, S.J.; Sukhatme, V.V. Fluvoxamine: A Review of Its Mechanism of Action and Its Role in COVID-19. Front. Pharmacol. 2021, 12, 652688. [CrossRef]

14. Bialek, K.; Czarny, P.; Wigner, P.; Synowiec, E.; Barszczewska, G.; Bijak, M.; Szemraj, J.; Niemczyk, M.; Tota-Glowczyk, K.; Papp, M.; et al. Chronic Mild Stress and Venlafaxine Treatment Were Associated with Altered Expression Level and Methylation Status of New Candidate Inflammatory Genes in PBMCs and Brain Structures of Wistar Rats. Genes 2021, 12, 667. [CrossRef]

15. Huang, C.; Wang, Y.; Li, X.; Ren, L.; Zhao, J.; Hu, Y.; Zhang, L.; Fan, G.; Xu, J.; Gu, X.; et al. Clinical features of patients infected with 2019 novel coronavirus in Wuhan, China. Lancet 2020, 395, 497-506. [CrossRef]

16. Mehta, P.; McAuley, D.F.; Brown, M.; Sanchez, E.; Tattersall, R.S.; Manson, J.J.; HLH Across Speciality Collaboration, UK. COVID-19: Consider cytokine storm syndromes and immunosuppression. Lancet 2020, 395, 1033-1034. [CrossRef]

17. Lee, S.; Yu, Y.; Trimpert, J.; Benthani, F.; Mairhofer, M.; Richter-Pechanska, P.; Wyler, E.; Belenki, D.; Kaltenbrunner, S.; Pammer, M.; et al. Virus-induced senescence is a driver and therapeutic target in COVID-19. Nature 2021, 599, 283-289. [CrossRef]

18. Leonard, B.E.; Myint, A. Changes in the immune system in depression and dementia: Causal or coincidental effects? Dialogues Clin. Neurosci. 2006, 8, 163-174.

19. Hannestad, J.; DellaGioia, N.; Bloch, M.H. The Effect of Antidepressant Medication Treatment on Serum Levels of Inflammatory Cytokines: A Meta-Analysis. Neuropsychopharmacology 2011, 36, 2452-2459. [CrossRef]

20. Hamed, M.; Hagag, R.S. The possible immunoregulatory and anti-inflammatory effects of selective serotonin reuptake inhib-itors in coronavirus disease patients. Med. Hypotheses 2020, 144, 110140. [CrossRef]

21. Sen, A. Does serotonin deficiency lead to anosmia, ageusia, dysfunctional chemesthesis and increased severity of illness in COVID-19? Med. Hypotheses 2021, 153, 110627. [CrossRef] 
22. Taler, M.; Gil-Ad, I.; Lomnitski, L.; Korov, I.; Baharav, E.; Bar, M.; Zolokov, A.; Weizman, A. Immunomodulatory effect of selective serotonin reuptake inhibitors (SSRIs) on human T lymphocyte function and gene expression. Eur. Neuropsychopharmacol. 2007, 17, 774-780. [CrossRef] [PubMed]

23. Karki, R.; Sharma, B.R.; Tuladhar, S.; Williams, E.P.; Zalduondo, L.; Samir, P.; Zheng, M.; Sundaram, B.; Banoth, B.; Malireddi, R.; et al. Synergism of TNF- $\alpha$ and IFN- $\gamma$ Triggers In-flammatory Cell Death, Tissue Damage, and Mortality in SARS-CoV-2 Infection and Cytokine Shock Syndromes. Cell 2021, 184, 149-168. [CrossRef] [PubMed]

24. Majidpoor, J.; Mortezaee, K. Interleukin-6 in SARS-CoV-2 induced disease: Interactions and therapeutic applications. Biomed. Pharmacother. 2021, 145, 112419. [CrossRef] [PubMed]

25. Golden, S.R.; Rosenstein, D.L.; Belhorn, T.; Blatt, J. Repurposing Psychotropic Agents for Viral Disorders: Beyond COVID. ASSAY Drug Dev. Technol. 2021, 19, 373-385. [CrossRef] [PubMed]

26. Dechaumes, A.; Nekoua, M.P.; Belouzard, S.; Sane, F.; Engelmann, I.; Dubuisson, J.; Alidjinou, E.K.; Hober, D. Fluoxetine Can Inhibit SARS-CoV-2 In Vitro. Microorganisms 2021, 9, 339. [CrossRef] [PubMed]

27. Carpinteiro, A.; Edwards, M.J.; Hoffmann, M.; Kochs, G.; Gripp, B.; Weigang, S.; Adams, C.; Carpinteiro, E.; Gulbins, A.; Keitsch, S.; et al. Pharmacological inhibition of acid sphingomyelinase prevents uptake of SARS-CoV-2 by epithelial cells. Cell Rep. Med. 2020, 1, 100142. [CrossRef]

28. Hoertel, N.; Sánchez-Rico, M.; Cougoule, C.; Gulbins, E.; Kornhuber, J.; Carpinteiro, A.; Becker, K.A.; Reiersen, A.M.; Lenze, E.J.; Seftel, D.; et al. Repurposing antidepressants inhibiting the sphingomyelinase acid/ceramide system against COVID-19: Current evidence and potential mechanisms. Mol. Psychiatry 2021. [CrossRef]

29. Kornhuber, J.; Hoertel, N.; Gulbins, E. The acid sphingomyelinase/ceramide system in COVID-19. Mol. Psychiatry 2021, 2021, 1-8. [CrossRef]

30. Törnquist, K.; Asghar, M.Y.; Srinivasan, V.; Korhonen, L.; Lindholm, D. Sphingolipids as Modulators of SARS-CoV-2 Infection. Front. Cell Dev. Biol. 2021, 9, 689854. [CrossRef]

31. Rauchman, S. COVID: Treatment trials are still urgent. Nature 2021, 594, 26. [CrossRef]

32. Hsu, L.; Grüne, B.; Buess, M.; Joisten, C.; Klobucnik, J.; Nießen, J.; Patten, D.; Wolff, A.; Wiesmüller, G.A.; Kossow, A.; et al. COVID-19 Breakthrough Infections and Transmission Risk: Real-World Data Analyses from Germany's Largest Public Health Department (Cologne). Vaccines 2021, 9, 1267. [CrossRef] [PubMed]

33. Torjesen, I. COVID-19: Omicron may be more transmissible than other variants and partly resistant to existing vaccines, scientists fear. BMJ 2021, 375, n2943. [CrossRef] [PubMed]

34. Lenze, E.J.; Mattar, C.; Zorumski, C.F.; Stevens, A.; Schweiger, J.; Nicol, G.E.; Miller, J.P.; Yang, L.; Yingling, M.; Avidan, M.S.; et al. Fluvoxamine vs Placebo and Clinical 429 Deterioration in Outpatients with Symptomatic COVID-19: A Randomized Clinical Trial. JAMA 2020, 324, 2292-2300. [CrossRef]

35. Seftel, D.; Boulware, D.R. Prospective Cohort of Fluvoxamine for Early Treatment of Coronavirus Disease 19. Open Forum Infect. Dis. 2021, 8, ofab050. [CrossRef] [PubMed]

36. Reis, G.; dos Santos Moreira-Silva, E.A.; Silva DC, M.; Thabane, L.; Milagres, A.C.; Ferreira, T.S.; dos Santos, C.V.Q.; Campos, V.H.d.S.; Nogueira, A.M.R.; de Almeida, A.P.F.G.; et al. Effect of early treatment with fluvoxamine on risk of emergency care and hospitalisation among patients with COVID-19: The TOGETHER randomised, platform clinical trial. Lancet Glob. Health 2021, 10, e42-e51. [CrossRef]

37. Oskotsky, T.; Marić, I.; Tang, A.; Oskotsky, B.; Wong, R.J.; Aghaeepour, N.; Sirota, M.; Stevenson, D.K. Mortality Risk Among Patients With COVID-19 Prescribed Selective Serotonin Reuptake Inhibitor Antidepressants. JAMA Netw. Open 2021, 4, e2133090. [CrossRef]

38. Brody, D.J.; Gu, Q. Antidepressant Use among Adults: United States, 2015-2018. Hyattsville. 2020. Available online: https: / / www.cdc.gov/nchs/data/databriefs/db377-H.pdf (accessed on 23 November 2020).

39. Anagha, K.; Shihabudheen, P.; Uvais, N.A. Side Effect Profiles of Selective Serotonin Reuptake Inhibitors: A Cross-Sectional Study in a Naturalistic Setting. Prim. Care Companion CNS Disord. 2021, 23, 20m02747. [CrossRef]

40. Calusic, M.; Marcec, R.; Luksa, L.; Jurkovic, I.; Kovac, N.; Mihaljevic, S.; Likic, R. Safety and efficacy of fluvoxamine in COVID-19 ICU patients: An open label, prospective cohort trial with matched controls. Br. J. Clin. Pharmacol. 2021. Epub ahead of print. [CrossRef]

41. Clelland, C.L.; Ramiah, K.; Steinberg, L.; Clelland, J.D. Analysis of the impact of antidepressants and other medications on COVID-19 infection risk in a chronic psychiatric in-patient cohort. BJPsych Open 2021, 8, e6. [CrossRef]

42. Bainum, T.B.; Fike, D.S.; Mechelay, D.; Haase, K.K. Effect of Abrupt Discontinuation of Antidepressants in Critically Ill Hospitalized Adults. J. Hum. Pharmacol. Drug Ther. 2017, 37, 1231-1240. [CrossRef]

43. Kelly, J.M.; Rubenfeld, G.D.; Masson, N.; Min, A.; Adhikari, N.K.J. Using Selective Serotonin Reuptake Inhibitors and Seroto-ninNorepinephrine Reuptake Inhibitors in Critical Care: A Systematic Review of the Evidence for Benefit or Harm. Crit. Care Med. 2017, 45, e607-e616. [CrossRef] [PubMed]

44. Halperin, D.; Reber, G. Influence of antidepressants on hemostasis. Dialogues Clin. Neurosci. 2007, 9, 47-59. [PubMed]

45. Pigott, T.A.; Pato, M.T.; L'Heureux, F.; Hill, J.L.; Grover, G.N.; Bernstein, S.E.; Murphy, D.L. A controlled comparison of adjuvant lithium carbonate or thyroid hormone in clomipramine-treated patients with obsessive-compulsive disorder. J. Clin. Psychopharmacol. 1991, 11, 242-248. [CrossRef] [PubMed] 
46. Gu, S.X.; Tyagi, T.; Jain, K.; Gu, V.W.; Lee, S.H.; Hwa, J.M.; Kwan, J.M.; Krause, D.S.; Lee, A.I.; Halene, S.; et al. Thrombocytopathy and endotheliopathy: Crucial contributors to COVID-19 thromboinflammation. Nat. Rev. Cardiol. 2021, 18, 194-209. [CrossRef]

47. Lohia, P.; Kapur, S.; Benjaram, S.; Cantor, Z.; Mahabadi, N.; Mir, T.; Badr, M.S. Statins and clinical outcomes in hospitalized COVID-19 patients with and without Diabetes Mellitus: A retrospective cohort study with propensity score matching. Cardiovasc. Diabetol. 2021, 20, 140. [CrossRef] [PubMed]

48. Lopes, R.D.; Macedo, A.V.S.; de Barros E Silva, P.G.M.; Moll-Bernardes, R.J.; Dos Santos, T.M.; Mazza, L.; Feldman, A.; Arruda, G.D.S.; de Albuquerque, D.C.; Camiletti, A.S.; et al. Effect of Discontinuing vs. Continuing Angiotensin-Converting Enzyme Inhibitors and Angiotensin II Receptor Blockers on Days Alive and Out of the Hospital in Patients Admitted with COVID-19: A Randomized Clinical Trial. JAMA 2021, 325, 254-264. [CrossRef] [PubMed]

49. Wang, Q.; Davis, P.B.; Gurney, M.E.; Xu, R. COVID-19 and dementia: Analyses of risk, disparity, and outcomes from electronic health records in the US. Alzheimer Dement. 2021, 17, 1297-1306. [CrossRef]

50. Hoertel, N. Do the Selective Serotonin Reuptake Inhibitor Antidepressants Fluoxetine and Fluvoxamine Reduce Mortality Among Patients With COVID-19? JAMA Netw. Open 2021, 4, e2136510. [CrossRef]

51. Rudrapatna, V.A.; Glicksberg, B.S.; Butte, A.J. Utility of routinely collected electronic health records data to support effectiveness evaluations in inflammatory bowel disease: A pilot study of tofacitinib. BMJ Health Care Inform. 2021, 28, e100337. [CrossRef] 